\title{
Predictive factors for local control of early glottic squamous cell carcinomas after definitive radiotherapy
}

\author{
MITSURU OKUBO, TOMOHIRO ITONAGA, TATSUHIKO SAITO, SACHIKA SHIRAISHI, RYUJI MIKAMI, \\ AKIRA SAKURADA, SHINJI SUGAHARA, JINHO PARK, KOICHI TOKUUYE and KAZUHIRO SAITO
}

Department of Radiology, Tokyo Medical University Hospital, Tokyo 160-0023, Japan

Received September 11, 2019; Accepted January 29, 2020

DOI: $10.3892 / \mathrm{mco} .2020 .2024$

\begin{abstract}
The aim of the present study was to retrospectively investigate the risk factors of local failure for T1 glottic carcinoma irradiated with a prescription dose of $66 \mathrm{~Gy}$. Between July 2006 and December 2017, 64 patients with T1 glottic squamous cell carcinoma treated with $66 \mathrm{~Gy} / 33$ fractions were analyzed for risk factors of local failure. The sex, age, performance status, $\mathrm{T}$ stage, overall treatment time, anterior commissure involvement, smoking status during/after treatment, histological tumor grade and pretreatment hemoglobin level were investigated. The maximum, mean and minimum doses, and the homogeneity index for the glottic larynx were calculated for dosimetric risk factors of local failure. The median follow-up duration was 51 months. Local failure was observed in 6 patients $(9.5 \%)$. Among all risk factors, only the minimum dose to the glottic larynx was found to be significantly associated with local failure $(\mathrm{P}=0.025)$. The 5-year local control rates for a minimum dose to the glottic larynx of $<65$ and $\geq 65$ Gy were 79 and $95 \%$, respectively, with a statistically significant difference $(\mathrm{P}=0.015)$. No patients exhibited grade $\geq 3$ late adverse effects. The minimum dose to the glottic larynx was the only factor significantly associated with local failure. Thus, local control of $\mathrm{T} 1$ glottic carcinoma may improve with a minimum dose of $\geq 65$ Gy to the glottic larynx. In conclusion, radiotherapy with a minimum prescription dose of $\geq 65$ Gy to the glottic larynx appears to be safe and achieves a high local control rate for $\mathrm{T} 1$ glottic carcinoma.
\end{abstract}

\section{Introduction}

Radiotherapy (RT) is a well-established treatment modality for patients with early laryngeal carcinoma; however, laser

Correspondence to: Dr Mitsuru Okubo, Department of Radiology, Tokyo Medical University Hospital, 6-7-1 Nishishinjuku, Shinjuku-ku, Tokyo 160-0023, Japan

E-mail: okubo@tokyo-med.ac.jp

Key words: predictive factors, early glottic carcinoma, definitive radiotherapy, local control, clinical risk factor, dosimetric risk factors therapy and partial laryngectomy may also be used to definitively treat early laryngeal carcinomas (1-3). The goals of treatment are cancer cure, preservation of the vocal cords with acceptable voice quality, and minimal treatment-related mortality. Definitive RT may achieve all these goals in the majority of patients with early laryngeal carcinoma, and salvage laryngectomy may be effective in cases of relapse. The local control rate for patients with early laryngeal carcinoma who undergo salvage laryngectomy for recurrence after initial RT is $90-100 \%$ (4-9).

Laryngeal carcinoma is classified into glottic, supraglottic and subglottic types according to the place of origin, with glottic carcinomas being the most common (70\%). The majority of glottic carcinomas are at an early stage and account for $\sim 70 \%$ of all cases. The most commonly used dose-fractionation schedule for T1 glottic carcinoma is 66 Gy/33 fractions. The local control rate for T1N0 glottic carcinoma treated with conventional fractionation is $80-90 \%(8,10-12)$. Thus, RT alone results in an adequate local control rate for $\mathrm{T} 1 \mathrm{glottic}$ lesions, with a low incidence rate of severe complications. However, some patients may experience local failure. The local control rate for $\mathrm{T} 1$ glottic carcinoma may be improved by identifying the risk factors for local failure. Therefore, the aim of the present study was to retrospectively investigate the risk factors of local failure in patients with T1 glottic carcinoma irradiated with a prescription dose of $66 \mathrm{~Gy}$.

\section{Patients and methods}

Patients. Between July 2006 and December 2017, 69 consecutive patients with early (T1) glottic squamous cell carcinoma were treated with definitive RT. All patients provided written informed consent, and the study was approved by the Ethics Review Board of the Tokyo Medical University Hospital (Tokyo, Japan). Among the 69 patients, 64 who underwent irradiation with a dose-fractionation schedule of $66 \mathrm{~Gy} / 33$ fractions were selected for the retrospective analysis. The characteristics of the 64 patients are listed in Table I. Tumor stage was defined according to the 2016 TNM classification (13) (8th edition, International Union Against Cancer). Of the 64 patients, 57 were men and 7 were women. The median patient age was 72 years (range, $47-86$ years). A total of $98 \%$ of the patients had an Eastern Cooperative Oncology Group performance status score of 0 or 1 . The primary tumor stage 
Table I. Patient and tumor characteristics $(n=64)$.

\begin{tabular}{lc}
\hline Characteristics & No. $(\%)$ \\
\hline Sex & \\
Male & $57(89)$ \\
Female & $7(11)$ \\
Age, years [median (range)] & $72(47-86)$ \\
Performance status score & \\
0 & 60 \\
1 & 3 \\
2 & 0 \\
3 & 1 \\
Stage of primary tumors & \\
T1a & $43(67)$ \\
T1b & $21(33)$ \\
Smoking during/after treatment & \\
Yes & $28(44)$ \\
No & $36(56)$ \\
Anterior commissure involvement by tumor & \\
Yes & $23(36)$ \\
No & $41(64)$ \\
Histological grade & \\
Well-differentiated & \\
Moderately/poorly differentiated & \\
Pretreatment hemoglobin level, g/dl & \\
$\leq 14$ & $25(39)$ \\
$>14$ & \\
\hline & \\
& \\
&
\end{tabular}

was T1a in 43 and T1b in 21 patients. None of the patients had clinical neck or distant metastasis. Among the 64 patients, 55 experienced hoarseness. In addition, 15 patients $(23 \%)$ had double cancers, $4(6 \%)$ had triple cancers, and $2(3 \%)$ had quadruple cancers, including the glottic tumor.

$R T$. Three-dimensional RT was planned and performed using a shell with the patient placed in the supine position. For treatment planning, all patients underwent cervical computed tomography (CT) with a $2.5 \mathrm{~mm}$ slice thickness. Treatment planning was performed using the Eclipse ${ }^{\mathrm{TM}}$ (Varian Medical Systems) treatment planning system. The standard RT technique involved parallel opposing lateral fields using photons of 4-MV X-rays for all patients over 5 days per week. The volume of the glottic larynx was defined as the vocal cord and was contoured by a single radiation oncologist. The gross tumor volume was defined based on endoscopy findings. However, it was not delineated in the present study, owing to non-visualization on $\mathrm{CT}$ and magnetic resonance imaging. The clinical target volume (CTV) encompassed the glottis, subglottis and part of the supraglottis; cranially and anteriorly, the CTV extended to the thyroid notch at the level of the vocal process of the arytenoid cartilage, and caudally and posteriorly it extended to the middle of the cricoid cartilage. A $5 \mathrm{~mm}$ isotropic expansion of the CTV provided the planning target volume (PTV). A typical contouring of the target volume and beam's eye view are shown in Fig. 1. Irradiation was delivered via local portals (mostly 5-6x5-6 cm) covering only the primary lesion. The cervical lymph nodes were not electively treated. The dose and fractionation for all patients was $66 \mathrm{~Gy} / 33$ fractions delivered over 6.6 weeks.

Evaluation of local response and adverse effects. The local response was evaluated by laryngoscopy at 1 month after completion of RT. In the absence of clinical symptoms, regular follow-up visits were performed at 2-3-month intervals for the first 2 years, and every 4-6 months thereafter. At each follow-up visit, the evaluation included laryngoscopy, medical history taking, physical examination, CT, and tumor marker assessment. The data pertaining to adverse effects were collected retrospectively from patient files. Local failure was considered to occur when local recurrence developed after an initial complete response. The Common Terminology Criteria for Adverse Events (14), version 3.0 (CTCAE v3.0) were used for evaluating the acute and late effects of RT.

Risk factors for local failure. The following factors were investigated to determine the clinical risk factors for local failure: Sex, age, performance status, T stage, overall treatment time (OTT), anterior commissure involvement (ACI), smoking status during/after treatment, histological tumor grade, and pretreatment hemoglobin levels. The pretreatment hemoglobin level was measured within 1 month prior to the initiation of RT. The maximum, mean and minimum doses and the homogeneity index (HI) for the glottic larynx, CTV and PTV were evaluated as dosimetric risk factors for local failure. The HI was calculated as the maximum dose divided by the minimum dose to the target volume (15).

Statistical analysis. The endpoint was local control, calculated from the first date of RT. The associations between local failure and the clinical factors were calculated using the Fisher's exact probability test. The associations between local failure and dosimetric factors were analyzed using the Mann-Whitney U test. The local control rate was plotted using the Kaplan-Meier method, with statistical significance assessed by the log-rank test. Univariate logistic regression analyses were performed to evaluate the data using SPSS 20.0 (IBM Corp.). Differences with P-values $<0.05$ were considered statistically significant.

\section{Results}

Local control and overall survival. The median follow-up duration was 51 months (range, 4-132 months). All patients with local failure of the primary lesion treatment who were successfully salvaged by surgery were considered to have had local failure with RT. The overall survival and local control curves are shown in Figs. 2 and 3. The 5-year overall survival rate was $96 \%$, and $2(3.1 \%)$ of the 64 cases died from gastric cancer and pneumonia. The 5-year local control rate was $92 \%$, and local failure was observed in $6(9.5 \%)$ of the 64 cases; local failure alone occurred in 5 patients, whereas local failure and neck metastasis occurred in 1 patient. The median time for local failure was 12 months (range, 2-94 months) after the start of RT. 

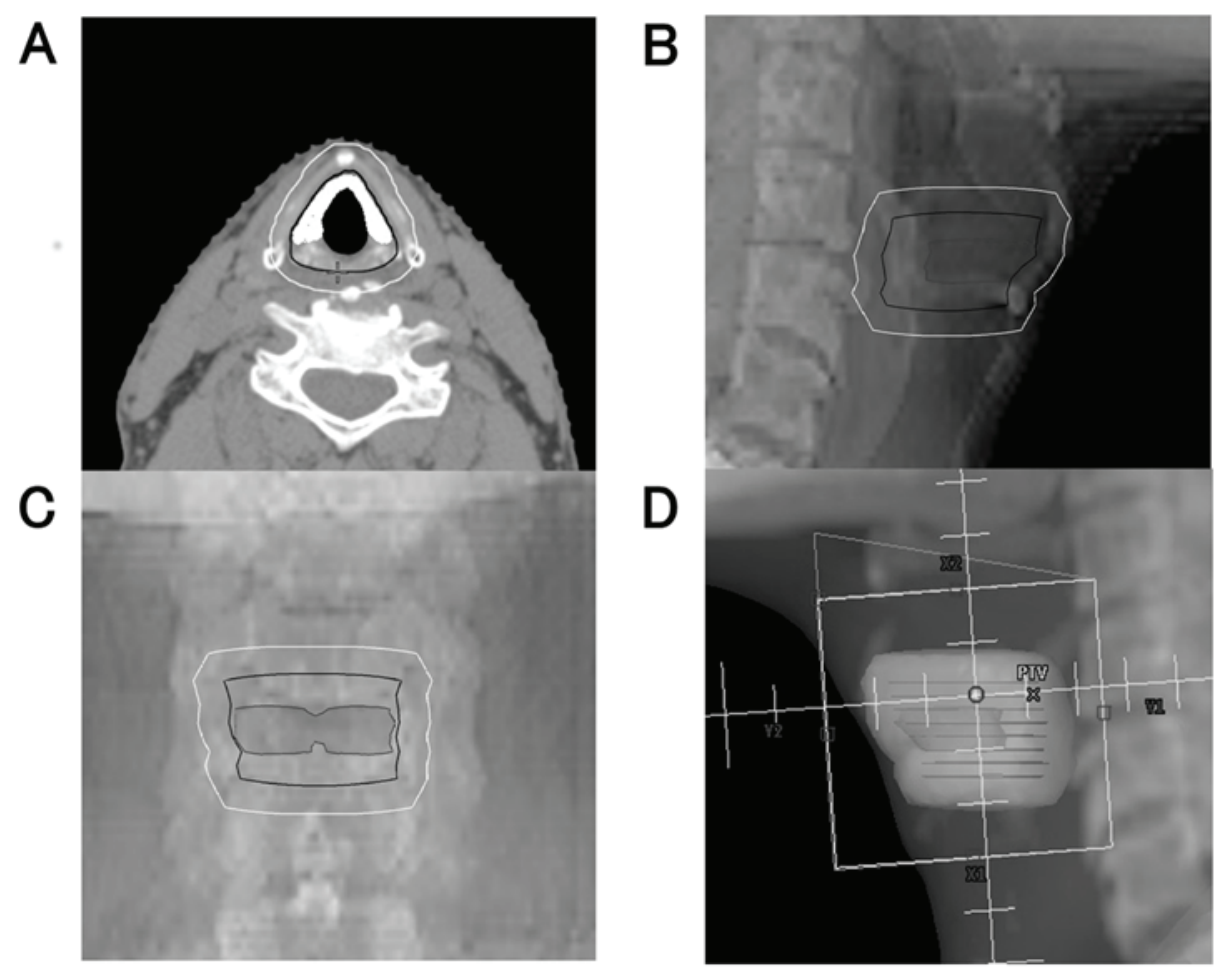

Figure 1. Typical contouring of the target volume and beam's eye view. (A) CT image for RT planning. The full white, black line and white line show the glottic larynx, CTV and PTV, respectively. (B and C) Sagittal and coronal tomography images for RT planning. (D) Beam's eye view of the typical field for RT planning. CT, computed tomography; RT, radiotherapy; CTV, clinical target volume; PTV, planning target volume.

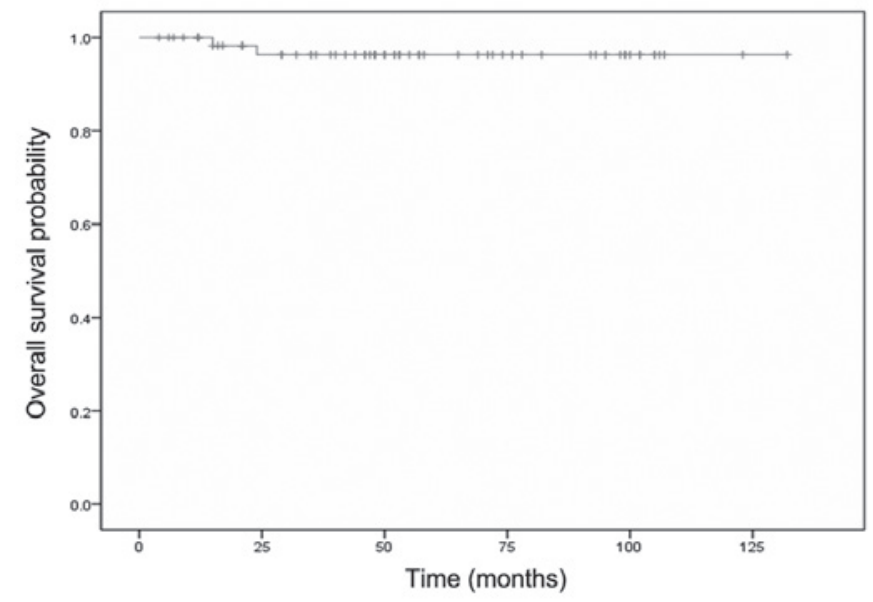

Figure 2. Overall survival curve. The 5-year overall survival rate was $96 \%$, and $2(3.1 \%)$ of the 64 patients died from other causes.

The associations between the clinical factors and local failure are summarized in Table II. No factor exhibited a significant association. Multivariate analysis was not performed owing to the limited data. The associations between the dosimetric factors and local failure in all the patients are shown in Table III. On univariate analysis, the minimum dose to the glottic larynx, calculated using Mann-Whitney $\mathrm{U}$ test, was the only factor significantly associated with the occurrence of local failure $(\mathrm{P}=0.025)$. The median minimum dose to the glottic larynx was $\sim 65 \mathrm{~Gy}$. The 5-year local control rates for patients with minimum doses to the glottic larynx of $<65$ and $\geq 65$ Gy were 79 and $95 \%$, respectively (Fig. 4).

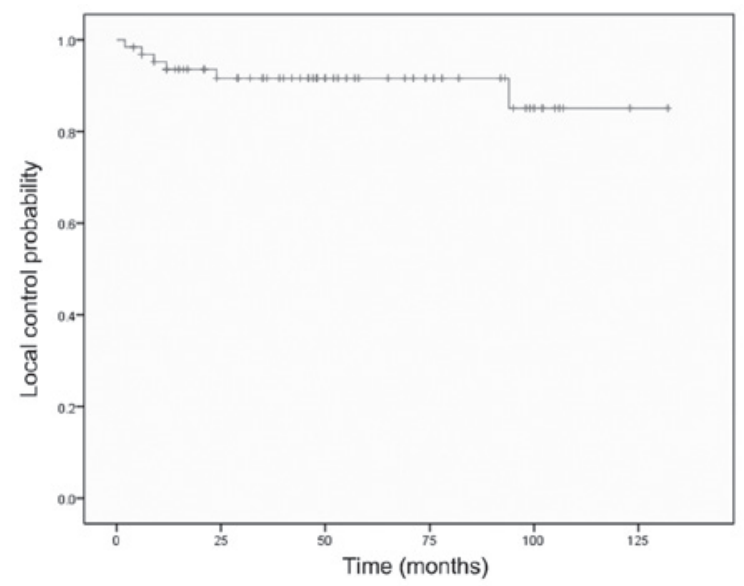

Figure 3. Local control curve. The 5-year local control rate was $92 \%$, and local failure was observed in $6(9.5 \%)$ of the 64 cases; local failure alone occurred in 5 patients and local failure with neck metastasis occurred in 1 patient.

The difference in the local control rate between patients who received $<65$ and $\geq 65$ Gy as the minimum dose to the glottic larynx, calculated using the log-rank test, was statistically significant $(\mathrm{P}=0.015)$.

Adverse effects. The acute and late adverse effects of RT are shown in Table IV. Of the 64 patients, 16 (25\%) had grade 2 acute dermatitis and $2(3 \%)$ had grade 3 acute dermatitis. Although 28 patients $(44 \%)$ had grade 2 acute mucositis, none demonstrated acute adverse effects or late adverse effects of grade $\geq 3$.

The clinical data and dosimetric factors for all cases are listed in Tables V and VI. 
Table II. Clinical risk factors associated with local failure.

\begin{tabular}{|c|c|c|c|}
\hline \multirow[b]{2}{*}{ Risk factors } & \multirow[b]{2}{*}{ Local failure, $n=6$} & \multicolumn{2}{|c|}{ Univariate analysis } \\
\hline & & P-value & Hazard ratio $(95 \% \mathrm{CI})$ \\
\hline Sex (male vs. female) & $11 \%(6 / 57)$ vs. $0 \%(0 / 7)$ & $>0.999$ & Uncomputable \\
\hline Age, years (<75 vs. $\geq 75)$ & $10 \%(4 / 39)$ vs. $8 \%(2 / 25)$ & $>0.999$ & $0.837(0.086-8.106)$ \\
\hline PS score $(0$ vs. $\geq 1)$ & $10 \%(6 / 60)$ vs. $0 \%(0 / 4)$ & $>0.999$ & Uncomputable \\
\hline T stage (T1a vs. T1b) & $12 \%(5 / 43)$ vs. $5 \%(1 / 21)$ & 0.654 & $3.481(0.282-42.978)$ \\
\hline OTT ( $\leq 49$ vs. $>49)$ & $11 \%(6 / 56)$ vs. $0 \%(0 / 8)$ & $>0.999$ & Uncomputable \\
\hline ACI (yes vs. no) & $9 \%(2 / 23)$ vs. $10 \%(4 / 41)$ & $>0.999$ & $1.622(0.231-11.395)$ \\
\hline $\begin{array}{l}\text { Smoking during/after treatment } \\
\text { (yes vs. no) }\end{array}$ & $11 \%(3 / 28)$ vs. $8 \%(3 / 36)$ & $>0.999$ & $1.109(0.141-8.708)$ \\
\hline $\begin{array}{l}\text { Histological tumor grade (well vs. } \\
\text { moderately/poorly differentiated) }\end{array}$ & $7 \%(3 / 45)$ vs. $16 \%(3 / 19)$ & 0.351 & $0.567(0.099-3.251)$ \\
\hline $\begin{array}{l}\text { Pretreatment hemoglobin level, } \\
\mathrm{g} / \mathrm{dl}(\leq 14 \text { vs. }>14)\end{array}$ & $4 \%(1 / 25)$ vs. $13 \%(5 / 39)$ & 0.391 & $1.273(0.107-15.196)$ \\
\hline
\end{tabular}

PS, performance status; OTT, overall treatment time; ACI, anterior commissure involvement; CI, confidence interval.

Table III. Association between dosimetric factors and local failure.

\begin{tabular}{lccc}
\hline & \multicolumn{2}{c}{ Local failure } & \\
\cline { 2 - 3 } Dose, Gy & Yes & No & P-value \\
\hline Glottic larynx & & & \\
Max dose & $69.0(66.6-71.8)$ & $69.0(66.6-71.8)$ & 0.613 \\
Mean dose & $66.7(65.6-68.4)$ & $67.1(64.9-69.9)$ & 0.478 \\
Min dose & $64.6(64.2-65.4)$ & $65.6(62.7-69.4)$ & 0.025 \\
HI & $1.06(1.02-1.09)$ & $1.04(1.00-1.08)$ & 0.053 \\
CTV & & & \\
Max dose & $68.8(66.2-71.1)$ & $68.8(66.5-71.8)$ & 0.920 \\
Mean dose & $65.7(65.0-66.9)$ & $65.8(64.6-68.9)$ & 0.506 \\
Min dose & $62.3(61.1-62.7)$ & $62.1(52.1-66.6)$ & 0.728 \\
HI & $1.11(1.06-1.14)$ & $1.11(1.04-1.34)$ & 0.728 \\
PTV & & & \\
Max dose & $69.0(66.5-71.1)$ & $68.9(66.6-71.8)$ & 0.991 \\
Mean dose & $65.4(64.5-66.2)$ & $65.3(63.8-68.0)$ & 0.866 \\
Min dose & $52.1(22.9-57.8)$ & $40.4(8.9-60.5)$ & 0.122 \\
HI & $1.34(1.15-3.09)$ & $1.69(1.11-7.88)$ & 0.106 \\
& & &
\end{tabular}

Doses are presented as mean (range). HI, homogeneity index; CTV, clinical target volume; PTV, planning target volume.

\section{Discussion}

In the present study, the 5-year local control rates for T1 glottic carcinomas treated with minimum doses of $<65$ and $\geq 65$ Gy to the glottic larynx were 79 and $95 \%$, respectively. The difference in the local control rate between patients treated with minimum doses of $<65$ and $\geq 65$ Gy to the glottic larynx was statistically significant $(\mathrm{P}=0.015)$.
Table IV. Acute and late radiation-related toxicities.

\begin{tabular}{lllll}
\hline & \multicolumn{4}{c}{ Grade } \\
\cline { 2 - 5 } Toxicities & 0 or 1 & 2 & 3 & 4 \\
\hline Acute & & & & \\
$\quad$ Dermatitis & 46 & 16 & 2 & 0 \\
Mucositis & 36 & 28 & 0 & 0 \\
Late & & & & \\
Laryngeal edema & 64 & 0 & 0 & 0 \\
Dermatitis & 64 & 0 & 0 & 0 \\
Myelopathy & 64 & 0 & 0 & 0 \\
\hline
\end{tabular}

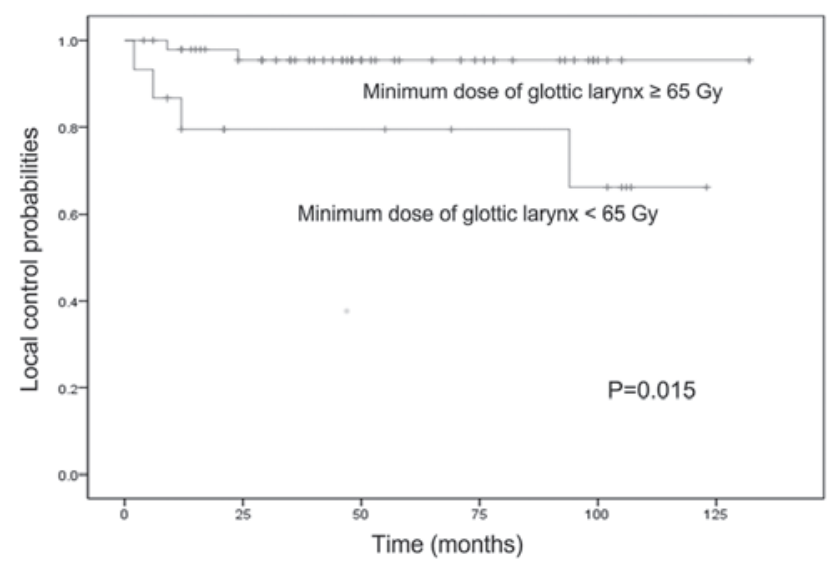

Figure 4 . The 5 -year local control rates for patients with minimum doses to the glottic larynx of $<65$ and $\geq 65$ Gy were 79 and $95 \%$, respectively. The difference was considered as statistically significant $(\mathrm{P}=0.015)$.

Several previous studies have reported on the risk factors for local failure in patients with $\mathrm{T} 1$ glottic carcinoma. The 
Table V. Clinical risk factors for local failure in all cases.

\begin{tabular}{|c|c|c|c|c|c|c|c|c|c|}
\hline No. & $\begin{array}{l}\text { Age, } \\
\text { years }\end{array}$ & Sex & $\begin{array}{c}\text { PS } \\
\text { score }\end{array}$ & T stage & $\begin{array}{c}\text { OTT } \\
\text { (days) }\end{array}$ & $\begin{array}{c}\text { ACI } \\
\text { (yes vs. no) }\end{array}$ & $\begin{array}{c}\text { Smoking } \\
\text { (yes vs. no) }\end{array}$ & $\begin{array}{c}\text { Histological tumor } \\
\text { grade (well vs. } \\
\text { moderate/poorly differentiated) }\end{array}$ & $\begin{array}{l}\text { Pretreatment } \\
\text { hemoglobin } \\
\quad(\mathrm{g} / \mathrm{dl})\end{array}$ \\
\hline 1 & 52 & M & 0 & $1 \mathrm{a}$ & 45 & Yes & Yes & Well & 14.6 \\
\hline 2 & 73 & M & 0 & $1 b$ & 46 & Yes & Yes & Well & 15 \\
\hline 3 & 65 & M & 0 & $1 b$ & 50 & Yes & Yes & Well & 14.8 \\
\hline 4 & 80 & M & 0 & $1 \mathrm{a}$ & 45 & Yes & No & Well & 14.4 \\
\hline 5 & 79 & M & 0 & $1 \mathrm{a}$ & 47 & No & No & Well & 15.6 \\
\hline 6 & 77 & $\mathrm{~F}$ & 0 & $1 b$ & 45 & Yes & No & Well & 11 \\
\hline 7 & 57 & M & 0 & $1 \mathrm{a}$ & 44 & No & Yes & Moderate-poor & 15.7 \\
\hline 8 & 83 & M & 0 & $1 b$ & 45 & Yes & No & Well & 15.4 \\
\hline 9 & 65 & $\mathrm{~F}$ & 0 & $1 \mathrm{a}$ & 45 & No & No & Moderate-poor & 14.5 \\
\hline 10 & 55 & $\mathrm{~F}$ & 0 & $1 \mathrm{a}$ & 47 & Yes & No & Well & 13 \\
\hline 11 & 75 & M & 0 & $1 \mathrm{a}$ & 44 & No & No & Well & 13.2 \\
\hline 12 & 63 & M & 0 & $1 b$ & 44 & Yes & No & Well & 15.5 \\
\hline 13 & 58 & $\mathrm{~F}$ & 0 & $1 \mathrm{a}$ & 39 & No & No & Well & 14.5 \\
\hline 14 & 47 & M & 0 & $1 \mathrm{a}$ & 50 & No & Yes & Well & 14 \\
\hline 15 & 71 & M & 3 & $1 \mathrm{a}$ & 46 & Yes & Yes & Moderate-poor & 11.3 \\
\hline 16 & 72 & M & 0 & $1 b$ & 49 & No & No & Well & 14.7 \\
\hline 17 & 73 & M & 0 & $1 \mathrm{a}$ & 44 & No & Yes & Moderate-poor & 15.9 \\
\hline 18 & 76 & M & 0 & $1 \mathrm{a}$ & 47 & No & No & Moderate-poor & 14.9 \\
\hline 19 & 64 & M & 0 & $1 \mathrm{a}$ & 51 & No & Yes & Well & 15.6 \\
\hline 20 & 71 & M & 0 & $1 \mathrm{a}$ & 45 & No & Yes & Moderate-poor & 14.8 \\
\hline 21 & 73 & M & 0 & $1 b$ & 50 & No & Yes & Well & 12.4 \\
\hline 22 & 76 & M & 0 & $1 \mathrm{a}$ & 50 & Yes & No & Well & 14.5 \\
\hline 23 & 84 & M & 0 & $1 \mathrm{a}$ & 45 & No & No & Well & 14.3 \\
\hline 24 & 70 & M & 0 & $1 \mathrm{a}$ & 45 & No & No & Moderate-poor & 16.5 \\
\hline 25 & 65 & M & 0 & $1 b$ & 44 & No & Yes & Well & 13.6 \\
\hline 26 & 70 & M & 0 & $1 \mathrm{a}$ & 47 & No & Yes & Well & 15.9 \\
\hline 27 & 73 & M & 0 & $1 \mathrm{a}$ & 43 & No & No & Well & 10.6 \\
\hline 28 & 70 & M & 0 & $1 \mathrm{a}$ & 44 & No & Yes & Moderate-poor & 15.1 \\
\hline 29 & 82 & M & 0 & $1 \mathrm{a}$ & 45 & No & No & Moderate-poor & 14.3 \\
\hline 30 & 65 & M & 0 & $1 b$ & 46 & Yes & No & Well & 14.4 \\
\hline 31 & 58 & M & 0 & $1 \mathrm{a}$ & 43 & No & Yes & Well & 14.2 \\
\hline 32 & 64 & M & 0 & $1 b$ & 45 & Yes & No & Moderate-poor & 14 \\
\hline 33 & 69 & M & 0 & $1 \mathrm{a}$ & 46 & No & Yes & Well & 13.6 \\
\hline 34 & 75 & M & 0 & $1 \mathrm{a}$ & 46 & No & No & Moderate-poor & 14.4 \\
\hline 35 & 70 & M & 0 & $1 \mathrm{a}$ & 45 & Yes & Yes & Moderate-poor & 14.8 \\
\hline 36 & 73 & M & 0 & $1 b$ & 46 & Yes & No & Well & 18 \\
\hline 37 & 86 & M & 1 & $1 \mathrm{a}$ & 49 & No & No & Well & 15 \\
\hline 38 & 81 & M & 0 & $1 \mathrm{a}$ & 48 & No & No & Well & 12.4 \\
\hline 39 & 80 & M & 0 & $1 b$ & 44 & yes & No & Well & 13.6 \\
\hline 40 & 86 & M & 0 & $1 \mathrm{a}$ & 46 & No & No & Well & 12.4 \\
\hline 41 & 70 & M & 0 & $1 b$ & 44 & No & No & Well & 15.9 \\
\hline 42 & 84 & M & 0 & $1 \mathrm{a}$ & 50 & No & No & Moderate-poor & 13.3 \\
\hline 43 & 63 & $\mathrm{~F}$ & 0 & $1 \mathrm{a}$ & 49 & No & Yes & Well & 13.2 \\
\hline 44 & 70 & M & 0 & $1 \mathrm{a}$ & 44 & No & No & Well & 15 \\
\hline 45 & 77 & M & 0 & $1 \mathrm{a}$ & 48 & No & No & Well & 14 \\
\hline 46 & 79 & M & 0 & $1 \mathrm{a}$ & 49 & No & Yes & Well & 12.6 \\
\hline 47 & 64 & $\mathrm{~F}$ & 0 & $1 \mathrm{a}$ & 52 & No & No & Well & 13.6 \\
\hline 48 & 66 & M & 0 & $1 \mathrm{a}$ & 51 & Yes & Yes & Well & 15.5 \\
\hline 49 & 84 & $\mathrm{M}$ & 0 & $1 \mathrm{a}$ & 44 & Yes & No & Well & 15.2 \\
\hline
\end{tabular}


Table V. Continued.

\begin{tabular}{|c|c|c|c|c|c|c|c|c|c|}
\hline No. & $\begin{array}{l}\text { Age, } \\
\text { years }\end{array}$ & Sex & $\begin{array}{l}\text { PS } \\
\text { score }\end{array}$ & T stage & $\begin{array}{c}\text { OTT } \\
\text { (days) }\end{array}$ & $\begin{array}{c}\text { ACI } \\
\text { (yes vs. no) }\end{array}$ & $\begin{array}{l}\text { Smoking } \\
\text { (yes vs. no) }\end{array}$ & $\begin{array}{l}\text { Histological tumor } \\
\text { grade (well vs. moderate/ } \\
\text { poorly differentiated) }\end{array}$ & $\begin{array}{l}\text { Pretreatment } \\
\text { hemoglobin } \\
\quad(\mathrm{g} / \mathrm{dl})\end{array}$ \\
\hline 50 & 84 & M & 1 & $1 \mathrm{a}$ & 44 & No & No & Moderate-poor & 11 \\
\hline 51 & 85 & M & 0 & $1 b$ & 45 & Yes & No & Well & 13.6 \\
\hline 52 & 72 & M & 0 & $1 b$ & 48 & Yes & Yes & Moderate-poor & 14.9 \\
\hline 53 & 72 & M & 0 & $1 b$ & 45 & No & Yes & Well & 12.5 \\
\hline 54 & 66 & M & 0 & $1 \mathrm{~b}$ & 44 & No & Yes & Moderate-poor & 15.4 \\
\hline 55 & 80 & $\mathrm{~F}$ & 0 & $1 \mathrm{a}$ & 45 & No & No & Well & 13.8 \\
\hline 56 & 83 & M & 0 & $1 b$ & 44 & No & No & Well & 12.1 \\
\hline 57 & 67 & M & 0 & $1 \mathrm{a}$ & 44 & Yes & No & Moderate-poor & 16.6 \\
\hline 58 & 73 & M & 0 & $1 \mathrm{a}$ & 45 & No & Yes & Well & 15.8 \\
\hline 59 & 84 & M & 0 & $1 b$ & 49 & Yes & No & Moderate-poor & 13.4 \\
\hline 60 & 71 & M & 0 & $1 \mathrm{a}$ & 44 & No & Yes & Well & 16.2 \\
\hline 61 & 84 & M & 1 & $1 \mathrm{a}$ & 45 & No & Yes & Moderate-poor & 14.8 \\
\hline 62 & 70 & M & 0 & $1 \mathrm{~b}$ & 45 & Yes & Yes & Well & 14.2 \\
\hline 63 & 76 & M & 0 & $1 \mathrm{a}$ & 48 & No & Yes & Well & 14.3 \\
\hline 64 & 68 & M & 0 & $1 \mathrm{~b}$ & 48 & Yes & Yes & Well & 13.6 \\
\hline
\end{tabular}

OTT, overall treatment time; ACI, anterior commissure involvement; M, male; F, female; PS, performance status.

local control rate for $\mathrm{Tl}$ tumors with an overall treatment time of 42-49 days was previously reported to be significantly higher compared with that of tumors with corresponding treatment times of $>49$ days $(\mathrm{P}<0.02)(11)$. In addition, previous studies have demonstrated an association between low hemoglobin levels and poor local control, i.e., pre-treatment anemia was an adverse factor for survival in patients with early-stage glottic carcinoma $(16,17)$; this was not observed in the present study. There was a significant decrease in the 10-year overall survival rate in patients with pre-RT anemia compared with those without pre-RT anemia (52 vs. 68\%, respectively) (18). Furthermore, a recent systematic review and meta-analysis was performed to determine the risk factors for RT failure in early-stage glottic carcinoma (19). There was a higher risk of RT failure in male patients [relative risk $(\mathrm{RR})=0.927$, $\mathrm{P}<0.001$, patients with low hemoglobin levels $(\mathrm{R} R=0.891$, $\mathrm{P}<0.001)$, tumors with ACI $(\mathrm{RR}=0.904, \mathrm{P}<0.001)$, tobacco use during/after therapy $(\mathrm{RR}=0.824, \mathrm{P}<0.001)$, and 'bulky' tumors $(\mathrm{RR}=1.270, \mathrm{P}<0.001)$ or large tumors $(\mathrm{R}=1.332, \mathrm{P}<0.001)$. In most previous studies, sex, age, comorbidities, tobacco use during/after RT, alcohol consumption, hemoglobin level, tumor stage, ACI, tumor size/volume, subglottic extension and grade, among others, were predictive factors for the survival of patients with early glottic squamous cell carcinomas following definitive RT. By contrast, in the present study, none of these clinical factors were indicative of RT failure in early-stage glottic carcinoma.

To the best of our knowledge, only a few studies have evaluated the dosimetric risk factors for local failure. Several studies investigated the association between total dose and local failure in early glottic carcinomas (18,20-26). The majority of those studies compared the total dose between $\leq 66$ and $>66$ Gy with regard to local failure, which was not significantly different. The present study was the first to investigate the dosimetric factors of local failure for early-stage glottic carcinoma that was definitively irradiated to a prescription dose of $66 \mathrm{~Gy}$. Furthermore, in the present study, the HI for glottic larynx did not reach the required levels of significance to be considered as a confounding factor. However, the P-value was reasonably low, confirming its importance. This finding indicates that techniques using RT for uniform dose distribution to the target volume, such as intensity-modulated RT (IMRT), may improve the local control rate for early-stage glottic carcinoma treated with definitive RT. Only a limited number of studies have evaluated the treatment outcomes of IMRT for early-stage squamous cell carcinoma of the glottis $(27,28)$. In these studies, the local control rate did not differ significantly between patients treated with IMRT and those treated with RT. However, the prescription dose for patients treated with IMRT was $63 \mathrm{~Gy} / 28$ fractions. Therefore, there is potential for improving the local control rate in patients treated with IMRT by setting the prescription dose to $66 \mathrm{~Gy} / 33$ fractions, and the minimum dose of the glottic larynx to $\geq 65 \mathrm{~Gy}$.

The main limitation of the present study was the possible selection bias for the predictive factors owing to the retrospective nature of the study. Therefore, prospective studies are required in the future to confirm our findings.

In conclusion, the minimum dose to the glottic larynx was the only factor found to be significantly associated with the occurrence of local failure. Setting the minimum dose to the glottic larynx at $\geq 65$ Gy may improve the local control rate for early-stage glottic carcinomas irradiated to a prescription dose of $66 \mathrm{~Gy}$. 


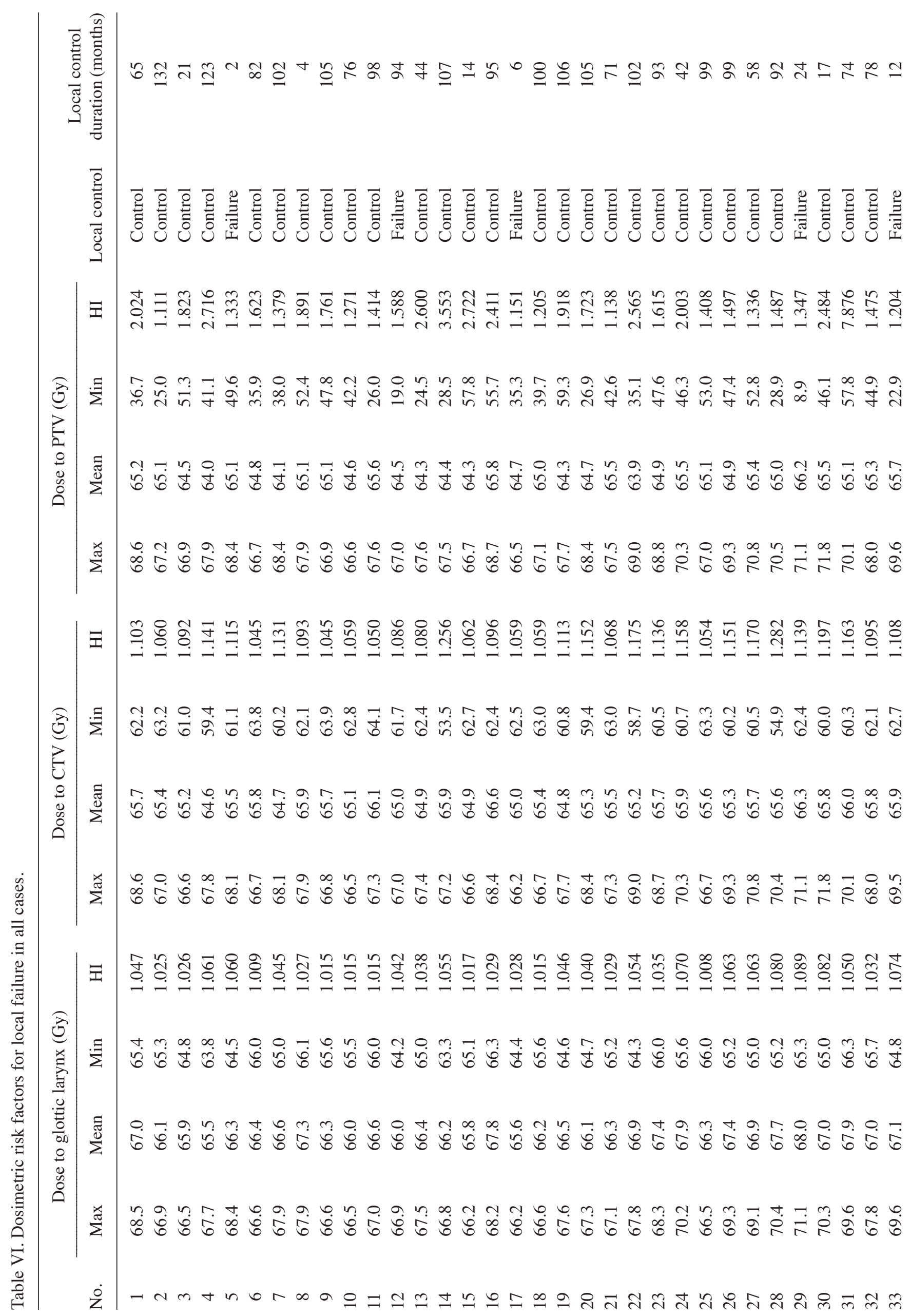




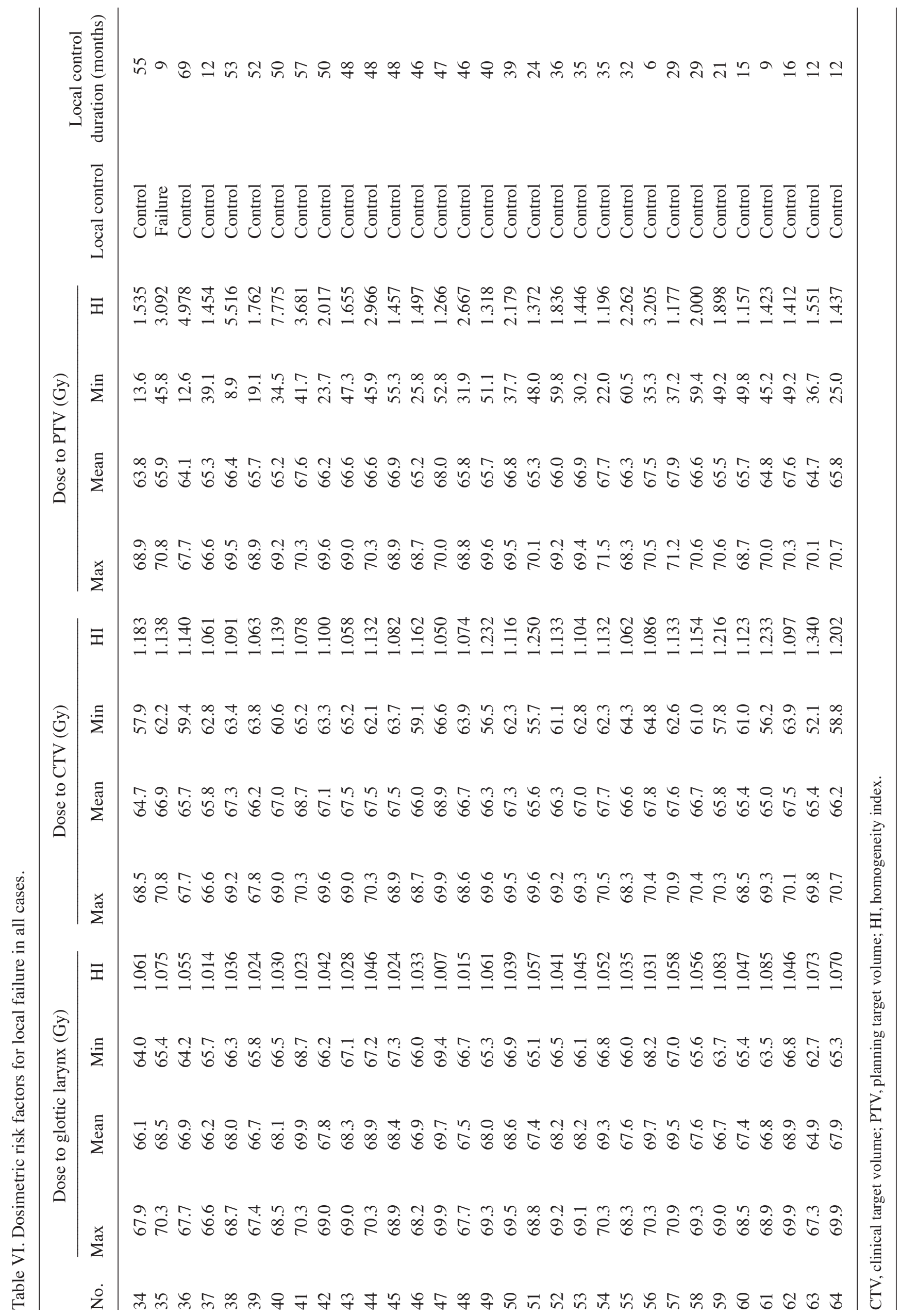




\section{Acknowledgements}

The authors wish to thank the radiographer Mr Hideaki Tiba, and Dr Yu Tajima, Department of Radiology, Tokyo Medical University Hospital, for their professional assistance.

\section{Funding}

No funding was received.

\section{Availability of data and materials}

The datasets used and/or analyzed during the present study are available from the corresponding author on reasonable request.

\section{Authors' contributions}

MO, TI, TS and ShS conceived the study, and wrote and revised the manuscript. RM, AS and $\mathrm{SaS}$ reviewed, collected and analyzed the data. JP, KT and KS designed the study and acquired the data. All authors contributed to the writing of the manuscript. All authors have read and approved the final manuscript.

\section{Ethics approval and consent to participate}

The present study was approved by the Institutional Review Board of Tokyo Medical University Hachioji Medical Center (Tokyo, Japan) and patient written informed consent was waived due to the retrospective design.

\section{Patient consent for publication}

Patient consent for publication was waived due to retrospective design.

\section{Competing interests}

The authors declare that they have no competing interests.

\section{References}

1. Mendenhall WM, Werning JW, Hinerman RW, Amdur RJ and Villaret DB: Management of T1-T2 glottic carcinomas. Cancer 100: 1786-1792, 2004.

2. Beitler JJ and Johnson JT: Transoral laser excision for early glottic cancer. Int J Radiat Oncol Biol Phys 56: 1063-1036, 2003.

3. Back $\mathrm{G}$ and Sood S: The management of early laryngeal cancer: Options for patients and therapists. Curr Opin Otolaryngol Head Neck Surg 13: 85-91, 2005.

4. Akine Y, Tokita N, Ogino T, Tsukiyama I, Egawa S, Saikawa M, Ohyama W, Yoshizumi T and Ebihara S: Radiotherapy of $\mathrm{T} 1$ glottic cancer with $6 \mathrm{MeV} \mathrm{X}$ rays. Int J Radiat Oncol Biol Phys 20: 1215-1218, 1991.

5. Fein DA, Lee WR, Hanlon AL, Ridge JA, Curran WJ and Coia LR: Do overall treatment time, field size, and treatment energy influence local control of T1-T2 squamous cell carcinomas of the glottic larynx? Int J Radiat Oncol Biol Phys 34: 823-831, 1996.

6. Mendenhall WM, Parsons JT, Stringer SP, Cassisi NJ and Million RR: T1-T2 vocal cord carcinoma: A basis for comparing the results of radiotherapy and surgery. Head Neck Surg 10: 373-377, 1988.
7. Rudoltz MS, Benammar A and Mohiuddin M: Prognostic factors for local control and survival in T1 squamous cell carcinoma of the glottis. Int J Radiat Oncol Biol Phys 26: 767-772, 1993.

8. Small W Jr, Mittal BB, Brand WN, Shetty RM, Rademaker AW, Beck GG and Hoover SV: Results of radiation therapy in early glottic carcinoma: Multivariate analysis of prognostic and radiation therapy variables. Radiology 183: 789-794, 1992.

9. Reddy SP, Hong RL, Nagda S and Emami B: Effect of tumor bulk on local control and survival of patients with T1 glottic cancer: A 30-year experience. Int J Radiat Oncol Biol Phys 69: 1389-1394, 2007.

10. Sakata K, Aoki Y, Karasawa K, Hasezawa K, Muta N, Nakagawa K, Terahara A, Onogi Y, Sasaki Y and Akanuma A: Radiation therapy in early glottic carcinoma: Uni- and multivariate analysis of prognostic factors affecting local control. Int J Radiat Oncol Biol Phys 30: 1059-1064, 1994.

11. Nishimura Y, Nagata Y, Okajima K, Mitsumori M, Hiraoka M, Masunaga S, Ono K, Shoji K and Kojima H: Radiation therapy for T1,2 glottic carcinoma: Impact of overall treatment time on local control. Radiother Oncol 40: 225-232, 1996.

12. Mendenhall WM, Parsons JT, Million RR and Fletcher GH: T1-T2 squamous cell carcinoma of the glottic larynx treated with radiation therapy: Relationship of dose-fractionation factors to local control and complications. Int J Radiat Oncol Biol Phys 15: 1267-1273, 1988.

13. Amin MB, Edge S, Greene F, Byrd DR, Brookland RK, Washington MK, Gershenwald JE, Compton CC, Hess KR, Sullivan DC et al (eds): AJCC Cancer Staging Manual. 8th edition. New York, Springer International Publishing, 2017.

14. National Cancer Institute. Common Terminology Criteria for Adverse Events (CTCAE) [Internet], 2018 (cited 2019 Aug 5). Available from: https://ctep.cancer.gov/protocoldevelopment/electronic_applications/ctc.htm\#ctc_50

15. Kataria T, Sharma K, Subramani V, Karrthick KP and Bisht SS: Homogeneity index: An objective tool for assessment of conformal radiation treatments. J Med Phys 37: 207-213, 2012.

16. Zhao KL, Liu G, Jiang GL, Wang Y, Zhong LJ, Wang Y, Yao WQ, Guo XM, Wu GD, Zhu LX, et al: Association of haemoglobin level with morbidity and mortality of patients with locally advanced oesophageal carcinoma undergoing radiotherapy-a secondary analysis of three consecutive clinical phase III trials. Clin Oncol (R Coll Radiol) 18: 621-627, 2006.

17. Shin NR, Lee YY, Kim SH, Choi CH, Kim TJ, Lee JW, Bae DS and Kim BG: Prognostic value of pretreatment hemoglobin level in patients with early cervical cancer. Obstet Gynecol Sci 57: 28-36, 2014.

18. Al-Mamgani A, van Rooij PH, Woutersen DP, Mehilal R, Tans L, Monserez D and aatenburg de Jong RJ: Radiotherapy for T1-2N0 glottic cancer: A multivariate analysis of predictive factors for the long-term outcome in 1050 patients and a prospective assessment of quality of life and voice handicap index in a subset of 233 patients. Clin Otolaryngol 38: 306-312, 2013.

19. Eskiizmir G, Baskın Y, Yalçın F, Ellidokuz H and Ferris RL: Risk factors for radiation failure in early-stage glottic carcinoma: A systematic review and meta-analysis. Oral Oncol 62: 90-100, 2016.

20. Franchin G, Minatel E, Gobitti C, Talamini R, Sartor G, Caruso G, Grando G, Politi D, Gigante M, Toffoli G, et al: Radiation treatment of glottic squamous cell carcinoma, stage I and II: Analysis of factors affecting prognosis. Int J Radiat Oncol Biol Phys 40: 541-548, 1998.

21. Marshak G, Brenner B, Shvero J, Shapira J, Ophir D, Hochman I, Marshak G, Sulkes A and Rakowsky E: Prognostic factors for local control of early glottic cancer: The Rabin Medical Center retrospective study on 207 patients. Int J Radiat Oncol Biol Phys 43: 1009-1013, 1999.

22. Narayana A, Vaughan AT, Kathuria S, Fisher SG, Walter SA and Reddy SP: P53 overexpression is associated with bulky tumor and poor local control in T1 glottic cancer. Int J Radiat Oncol Biol Phys 46: 21-26, 2000.

23. Cellai E, Frata P, Magrini SM, Paiar F, Barca R, Fondelli S, Polli C, Livi L, Bonetti B, Vitali E, et al: Radical radiotherapy for early glottic cancer: Results in a series of 1087 patients from two Italian radiation oncology centers. I. The case of T1N0 disease. Int J Radiat Oncol Biol Phys 63: 1378-1386, 2005.

24. Nur DA, Oguz C, Kemal ET, Ferhat E, Sülen S, Emel A, Münir K, Ann CS and Mehmet S: Prognostic factors in early glottic carcinoma implications for treatment. Tumori 91: 182-187, 2005. 
25. Murakami R, Nishimura R, Baba Y, Furusawa M, Ogata N, Yumoto E and Yamashita Y: Prognostic factors of glottic carcinomas treated with radiation therapy: Value of the adjacent sign on radiological examinations in the sixth edition of the UICC TNM staging system. Int J Radiat Oncol Biol Phys 61: 471-475, 2005.

26. Tong CC, Au KH, Ngan RK, Cheung FY, Chow SM, Fu YT, Au JS and Law SC: Definitive radiotherapy for early stage glottic cancer by 6 MV photons. Head Neck Oncol 4: 23, 2012.

27. Berwouts D, Swimberghe M, Duprez F, Boterberg T, Bonte K, Deron P, De Gersem W, De Neve W and Madani I: Intensity-modulated radiotherapy for early-stage glottic cancer. Head Neck 38 (Suppl 1): E179-E184, 2016.
28. Zumsteg ZS, Riaz N, Jaffery S, Hu M, Gelblum D, Zhou Y, Mychalczak B, Zelefsky MJ, Wolden S, Rao S and Lee NY: Carotid sparing intensity-modulated radiation therapy achieves comparable locoregional control to conventional radiotherapy in T1-2N0 laryngeal carcinoma. Oral Oncol 51: 716-723, 2015. 